\title{
Narrativas digitais das experiências docentes com o uso de tecnologias na educaçao básica
}

\author{
Adriana Azevedo ${ }^{1}$ \\ Maria da Conceição Passeggi²
}

\begin{abstract}
Resumo: O presente artigo apresenta parte de uma pesquisa sobre o uso das tecnologias digitais de informação e comunicação - TDIC - nas práticas pedagógicas de docentes da educação básica. $\mathrm{O}$ principal objetivo é o de avançar numa proposição reflexiva sobre as potencialidades de tais usos em ambiente educacional. $\mathrm{O}$ artigo mostra os modos como se procurou apreender a experiência de professores, que lidavam com frequência com recursos digitais. O intuito é o de buscar subsídios para uma reflexão sobre o uso de tecnologia na docência. A pesquisa foi realizada com onze professores das redes pública e privada dos municípios de São Bernardo do Campo e São Paulo, no segundo semestre de 2014. A escolha dos participantes se deu com base em conversas informais, em espaços educativos, com colegas professores, gestores e alunos de algumas escolas desses municípios, que os indicaram por utilizarem com frequência as TDIC em suas práticas pedagógicas. Do ponto de vista teóricometodológico, entrelaçam-se os princípios epistemológicos e do método da pesquisa (auto)biográfica, que norteiam a investigação científica em Educação, e a abordagem hermenêutico-fenomenológica sugerida por Maximina Freire (2012), enquanto modalidade de análise das fontes autobiográficas. O artigo apresenta a metodologia da constituição das fontes, mediante a escrita de narrativas digitais, discussões presenciais e a distância entre os participantes. Partiu-se de um convite aos participantes para refletirem sobre as seguintes questões: Quais experiências se tornaram referência em sua prática educativa com uso de tecnologias? O que o motiva a fazê-las? Como faz? Porque continua fazendo? O que daquilo que faz é relevante para a prática do outro? Como pode avançar? Os resultados da análise mostram que três grandes temas emergem das narrativas docentes: abertura, desafio e compromisso, cujos subtemas permitem aprofundar a ideia de que esses professores se afastam das modalidades e crenças tradicionais de ensino e aprendem a confiar nos alunos. $O$ desejo de aprender e de despertar no aluno o interesse pelo conhecimento fazem desses professores sujeitos mais autônomos em suas escolhas, o que lhes permite inventar caminhos pedagógicos, suscetíveis de serem trilhados por outros docentes.

Palavras Chave: Pesquisa (auto)biográfica, Abordagem hermenêutico-fenomenológica, Tecnologias digitais de informação e comunicação.
\end{abstract}

Abstract: This article presents part of a research about the use of digital information and communication technologies - TDIC - in pedagogical practices of teachers of basic education. The main objective is to propose a reflection about the potential of such uses in educational environment. The article shows the ways in which the experience was apprehended by teachers, who often dealt with digital resources. The aim is to seek subsidies for a reflection on the use of technology in teaching. The survey was conducted with eleven teachers from public and private schools in São Bernardo do Campo and São Paulo in the second semester of 2014. The selection of participants was made based on informal conversations in educational spaces, with fellow teachers, managers and students from some schools in the aforementioned cities, who often indicated the use of TDIC in their teaching practices. From a theoretical and methodological perspective, epistemological principles and (auto)biographical research method method are interwoven, which guide scientific research in education, and the hermeneutic-phenomenological approach suggested by Maximina Freire (2012), as a method for analysis of autobiographical sources. The article presents the methodology of the constitution of the sources through the writing of digital narratives, classroom and online discussions among participants. The starting point was an invitation to participants to reflect on the following questions: What experiences have become significant in their educational practice with the use of technology? What motivates to do them? How to do it? Why keep doing it? What is relevant to the practice of another? How can it advance? The analysis results show that three major themes emerge from the teachers' narratives: openness, challenge and commitment, whose subtopics allow TO deepen the idea that these teachers move away from traditional beliefs and ways of teaching and are learning to trust the students. The wish to learn and to awaken interest on the part of students make such teachers more autonomous in their choices, allowing them to invent educational paths, open to be followed by other teachers.

Keywords: (auto)biographical research, phenomenological hermeneutic approach, digital information and communication technologies.

\footnotetext{
${ }^{1}$ Docente permanente do Programa de Pós Graduação em Educação da Universidade Metodista de São Paulo.adriana.azevedo@metodista.br

2 Docente permanente do Programa de Pós Graduação em Educação da Universidade Federal do Rio Grande do Norte. Coordenadora do GRIFARS - Grupo Interdisciplinar de Pesquisa, Formação, Auto.Biografia, Representações e Subjetividade. mariapasseggi@ gmail.com
} 


\section{Introdução}

Com base nas vozes de professores da educação básica, este artigo propõe uma reflexão sobre suas percepções quanto a experiências vividas na docência com uso de tecnologias digitais. Focaliza-se como eles lidam com esses recursos, suas estratégias, escolhas e adaptações. O intuito da pesquisa é auxiliar os professores a adotarem mudanças necessárias em suas práticas, que lhes são impostas pela contemporaneidade. Do ponto de vista teórico-metodológico, a perspectiva adotada é a do entrelaçamento da pesquisa (auto)biográfica, seus princípios epistemológicos e de método que norteiam a investigação científica em Educação, com a abordagem hermenêutico-fenomenológica, enquanto modalidade utilizada para a análise das fontes autobiográficas.

Tomou-se a seguinte questão norteadora: Que percepções emergem sobre os usos de recursos digitais nas práticas pedagógicas dos professores, quando eles refletem sobre as experiências vividas com o uso de tecnologia na Educação Básica? Para tanto, os participantes foram convidados e motivados a refletirem sobre as seguintes questões: Quais experiências se tornaram referência em sua prática educativa com o uso de tecnologias? O que o motiva a fazê-las? Como as faz? Por que continua fazendo? O que daquilo que faz é relevante para a prática do outro? Como pode avançar?

Mais especificamente, apresenta-se neste artigo a metodologia utilizada para a constituição das fontes autobiográficas, a forma como se desencadeou a escrita das narrativas digitais e a interação, presencial e a distância, entre os docentes participantes. Procura-se mostrar ainda a importância do conceito de pesquisaformação, tal como ele é proposto por Marie-Christine Josso (2010), para a concepção do processo de organização e realização do curso de extensão denominado "A tecnologia na docência: construção de narrativas digitais". A intenção do curso foi promover um processo de reflexão biográfica em grupo reflexivo, como propõe Passeggi (2011), organizando uma "Rede de conversas", para a construção das narrativas digitais, que seriam posteriormente analisadas. A escrita das narrativas digitais foi realizada com a intenção de promover um processo reflexivo que pudesse contemplar essa busca de sentido das experiências vividas pelos professores. Nessa direção, a experiência de alguns docentes tem servido de inspiração para que possamos enxergar caminhos possíveis para a escola no contexto do século XXI.

\section{As narrativas digitais}

"A formação de formadores tem sido um dos domínios privilegiados de aplicação do método biográfico. O motivo parece óbvio: dificilmente poderemos pretender interferir na formação dos outros, sem antes termos procurado compreender o nosso próprio processo de formação" (NÓVOA; FINGER, 2010, p. 26). Nesse sentido, em meio a processos (auto)reflexivos buscou-se que os participantes refletissem sobre suas práticas docentes com o uso das TDIC. "Memória e profundidade são o mesmo, ou antes, a profundidade não pode ser alcançada pelo homem a não ser através da recordação" (ARENDT, 2005, p. 31), assim, os 11 (onze) participantes da pesquisa foram convidados formalmente a realizarem um curso de extensão, denominado "A tecnologia na docência: construção de narrativas digitais", oferecido pelas pesquisadoras. No convite estava explicitado que eles haviam sido escolhidos para fazer o curso porque as suas práticas pedagógicas com o uso de tecnologias se destacavam e elas eram consideradas relevantes por colegas professores e alunos de sua escola. 
Mesmo quando uma ação educativa se revela formadora, são na realidade os próprios adultos que se formam. A formação pertence, de fato, a quem se forma. É verdade que todo o adulto depende de apoios exteriores: ele é ajudado e apoiado por outros, e a sua formação acompanha o percurso da sua socialização. Mas, em última análise, tudo se decide numa lógica de apropriação individual, cuja explicação teórica nem sempre é possível. (NÓVOA e FINGER, 2010, p.31)

O referido curso de extensão universitária teve carga horária total de 45 horas, sendo 10 horas cumpridas em 2 (dois) encontros presenciais e 35 horas em Ambiente Virtual de Aprendizagem na modalidade EaD. Os participantes foram convidados a conhecer outros professores que, como eles, utilizavam a tecnologia para a promoção da aprendizagem. $\mathrm{O}$ curso foi estruturado em 4 (quatro) momentos distintos: $1^{\circ}$ Momento: encontro presencial com a apresentação dos participantes do projeto, discussão da proposta e reflexão sobre os insumos teóricos; $2^{\circ}$ Momento: atividades a distância, constituídas por três semanas de estudos e participações no Knowledge Fórum em um espaço próprio que chamamos de Rede de Conversas; $3^{\circ}$ Momento: segundo encontro presencial para compartilhamento das narrativas autobiográficas das práticas bem sucedidas com o uso de tecnologia digital; $4^{\circ}$ Momento: após encerramento da etapa de curso, cumpridas as 45 horas, os participantes foram convidados a organizar suas experiências no formato de artigos científicos, que serão publicados sob a forma de capítulos de um livro a ser lançado brevemente.

Desta forma, os procedimentos adotados no processo de pesquisa buscaram não somente os dados empíricos das narrativas, mas, sobretudo, oferecer aos participantes algo que pudesse dar sentido às suas reflexões e ações, que vinham sendo narradas com cumplicidade e confiança no espaço online Rede de Conversa, que se caracteriza como um espaço de pesquisa-formação:

Qualificamos esse cenário de "pesquisa-formação" porque a atividade de pesquisa contribui para a formação dos participantes no plano das aprendizagens reflexivas e interpretativas e toma lugar, no seu percurso de vida, como um momento de questionamento retroativo e prospectivo sobre seu(s) projeto(s) de vida e sua(s) demanda(s) de formação atual. Todos os grupos biográficos constatam que a apresentação e a escuta dos relatos desencadeiam um processo dialético de identificação (JOSSO, 2010, p. 71).

O curso foi organizado na intenção de promover um processo de reflexão biográfica em grupo reflexivo. Apresentamos aqui a síntese da proposta que compreendeu três movimentos geradores das narrativas autobiográficas que compõem o corpus de análise deste artigo. Com base nos estudos de Passeggi (2006/2008), os alunos foram convidados a realizar, durante esse período, os três movimentos concebidos pela autora no processo de mediação biográfica. O primeiro movimento de biografização compreende a dimensão iniciática, assim chamado em alusão ao ritual de ingresso na experiência da reflexão sobre si mesmo e à adesão ao trabalho comum. Esse primeiro movimento foi consagrado ao que denominamos "Tempos de aluno" e pautou-se pelas seguintes questões reflexivas: Como cheguei até aqui? Quais professores tinham práticas pedagógicas diferenciadas em suas aulas e por que me marcaram? O que faziam em sala de aula? Como faziam? Que práticas com o uso de tecnologia marcaram minha trajetória como aluno?

$\mathrm{O}$ segundo movimento correspondia à dimensão maiêutica da mediação biográfica, por sua mirada heurística no processo de biografização: compreender a 
experiência vivida significa compreender a si mesmo como agente e paciente de sua história (PASSEGGI, 2006/2008). Esse segundo movimento foi dedicado a pensar os "Tempos de Professor" e foi norteado pelas seguintes questões reflexivas: Quais experiências se tornaram referência em minha prática educativa com o uso de tecnologias? O que me motiva a fazê-las? Como as faço? Por que continuo fazendoas?

O terceiro e último movimento corresponde à dimensão hermenêutica da mediação biográfica e baseia-se na capacidade humana de tirar lições da experiência ao refletir sobre elas no processo de biografização, situando o saber que dela decorre numa perspectiva histórica, para melhor conhecer-se como sujeito histórico (PASSEGGI, 2006/2008). Esse último movimento, que denominamos Tempos de Partilhar, foi orientado pelas seguintes questões norteadoras: O que daquilo que tenho aprendido ou construí no meu percurso é relevante para a prática do outro? A partir das experiências compartilhadas, o que acredito poder fazer além do que já realizo hoje? Como posso avançar?

Conforme fica evidenciado pelas questões, a intenção do terceiro movimento era direcionar o narrador "a se distanciar cada vez mais de si para compreender quais foram suas aprendizagens, que lições tirar da experiência para agir, tomar decisões e projetar seu vir a ser"' (PASSEGGI, 2010, p. 52).

A cada semana de realização do curso, os participantes foram compreendendo e reconhecendo a importância da relação entre as narrativas, as discussões e os fóruns teóricos e compreendiam que tudo fazia parte de um processo de formação, tal como discutido por Delory-Momberger (2008, p. 89):

Esse reconhecimento biográfico traduz-se por um forte estímulo às pessoas em formação a fazerem um trabalho reflexivo sobre elas mesmas: realizando um balanço de seus percursos e de suas competências, inscrevendo sua formação num projeto pessoal e profissional e atestando, desse modo, sua formabilidade e sua empregabilidade.

O processo de reflexão biográfica, proporcionado pela experiência de pesquisa-formação, aqui relatada teve alguns momentos presencias e muitas vivências a distância. Dessa forma, se alternaram a escrita de si (autobiografia) e a compreensão de si pela história do outro (heterobiografia), conforme Passeggi (2006/2008). Mas também se desenvolve nesses três movimentos a consciência do sujeito singularplural, no sentido em que a pessoa que narra se autoconhece nas suas particularidades, em sua singularidade, e nos traços comuns com o grupo, ou seja, na sua própria pluralidade, como sugere Josso (2010).

Nessa reflexão também encontramos a dialética entre o individual e o coletivo, mas desta vez sob a forma de uma polaridade; de um lado, empenhamos a nossa interpretação (nos auto-interpretamos), e, por outro, procuramos no diálogo com os outros uma cointerpretação da nossa experiência. É neste movimento dialético que nos formamos como humanos, quer dizer: no polo da auto interpretação, como seres capazes de originalidade, de criatividade, de responsabilidade, de autonomização; mas, ao mesmo tempo, no polo da cointerpretação, partilhando um destino comum devido ao nosso pertencer a uma comunidade. É nessa polaridade que vivemos plenamente a nossa 
humanidade, nas suas dimensões individuais e coletivas (JOSSO, 2010, p. 54).

Ao concluir a etapa a distância, nos encontramos em um momento presencial de encerramento, onde todos puderam continuar presencialmente o diálogo que vinham desenvolvendo, de forma intensa, a distância e a partir das narrativas autobiográficas que haviam sido partilhadas. Todos puderam relatar suas percepções e vivências, enriquecendo os olhares sobre si, sobre suas experiências e as experiências do outro. Todos pareciam se sentir claramente provocados a continuar partilhando suas práticas. Para Bruner (2014, p. 76), "A autoconstrução é, no fim das contas, o nosso principal meio para estabelecer nossa singularidade, e uma breve reflexão deixa claro que nós nos distinguimos dos outros comparando nossos relatos com os relatos que os outros ofereceram sobre si mesmos". Assim, o autor afirma mais adiante que "o eu também é o outro" (op. cit. p. 76), e vimos que contar e ouvir histórias sobre as experiências vividas não é algo que se limita a uma perspectiva subjetivista, mas a uma construção de si pelo e no contato com o coletivo.

Saber de si é condição de possibilidade de viver bem, e não sabemos quem somos senão quando nos narramos em meio à participação. Ficou explicito que as ações pedagógicas positivamente diferenciadas realizadas pelos professores foram construídas num processo identitário de adesão, ação e autoconsciência, influenciadas pelas características pessoais e pelo percurso de vida profissional de cada professor.

\section{Análise das narrativas digitais}

Após apresentar sucintamente o processo de concepção, organização e realização da pesquisa, encontramos suporte para as análises na abordagem hermenêutico-fenomenológica, tal como sugerida por Maximina Freire (2012) a partir da associação de duas importantes correntes filosóficas: a fenomenologia e a hermenêutica, para compreender o que emergia das narrativas digitais dos docentes.

Para Maximina Freire (2012, p. 182;183), a abordagem hermenêuticofenomenológica, enquanto um método de pesquisa qualitativa, "contempla um interesse investigativo que é, essencialmente, baseado em experiências vividas uma vez que, como assegura McCoy (1993, p.4), "o mundo não é fundamentalmente o que se pensa sobre ele, mas o que nele se vive". Desta forma,

A abordagem hermenêutico-fenomenológica configura-se como uma orientação metodológica de natureza qualitativa, que visa descrever detalhadamente e interpretar fenômenos da experiência humana, objetivando aproximar-se de sua essência, por meio da identificação dos temas hermenêutico-fenomenológicos que os caracterizam e lhes dão identidade (FREIRE, M., 2012, p.194).

A abordagem hermenêutico-fenomenológica, utiliza-se das descrições das manifestações de um fenômeno da experiência humana, em formato textual textualização -, o que permite o desenvolvimento de uma atividade investigativa mais profunda, levando à apresentação de uma interpretação válida que "precisa ser documentada para que se mostre consistente e viável” (FREIRE, M., 2010, p. 25).

"A fenomenologia contempla as experiências vividas de um ponto de vista retrospectivo e descritivo, buscando desvendar a essência e as qualidades de um certo fenômeno, sob a perspectiva de quem o vivencia, percebe, intuitivamente interpreta e 
a ele se refere" (FREIRE, M., 2012, p. 185). Nesse sentido, Maximina Freire complementa afirmando que "a fenomenologia, portanto, procura um entendimento mais profundo das experiências cotidianas, preocupando-se com a forma como são imediatamente percebidas, ao invés de defini-las e/ou categorizá-las previamente" (FREIRE, M., 2012, p.185).

Complementarmente, para interpretar o mundo, a hermenêutica necessita de textos escritos, pois seu objetivo é decifrar, desvendar, revelar, interpretar, buscando os significados nas entrelinhas, no sentido de, a partir da aparência, buscar a essência das experiências humanas (RICOEUR, 2013, FREIRE M., 2010, 2012). Compreensão quer dizer algo que é apreendido em conjunto. A hermenêutica tem a ver com o nosso envolvimento no processo, a compreensão de si mesmo também está acontecendo. M. Freire (op.cit., p.186) lembra, citando Habermas, que "Ao inserir-se no mundo da linguagem, a hermenêutica renuncia a pretensão de verdade absoluta e reconhece que pertencemos às coisas ditas, aos discursos, abrindo uma infinidade de interpretações possíveis". A linguagem é, portanto, aquilo que ao atravessá-la, somos atravessados por ela, e, nessa dupla travessia, o que dizemos faz sentido, mesmo quando não nos damos conta disso.

O texto não é só o que ele significa, mas aquilo que dele se desdobra é a vida do texto. Somos intérpretes de nossas vidas e do mundo que nos rodeia. Nosso modo de ser é o do intérprete. Pois ao interpretar o que está diante de nós, estamos interpretando a nós mesmos. O intérprete interfere no texto e o texto interfere no intérprete. Atuamos como intérpretes e estamos nessa contínua (re)interpretação de si e do mundo.

A abordagem hermenêutico-fenomenológica possibilita, portanto, uma participação ativa e reflexiva do pesquisador como articulador e participante da pesquisa. Por essa razão, é que o pesquisador também se forma na e pela pesquisa. $\mathrm{Na}$ pesquisa-formação a atividade permanente de interpretações e construções de significado, realizada pelo pesquisador em busca de uma compreensão mais aprofundada do fenômeno investigado, se revela, assim, como um momento constitutivo de sua própria formação envolvida na experiência da pesquisa qualitativa.

Ao interpretar, eu me vejo em transformação. O si mesmo nunca está pronto. O si mesmo é tarefa- que passa pela interpretação. Interpretando o mundo, nós fazemos a tarefa de melhorar a nós mesmos e no conflito das interpretações é sempre importante haver diálogo, como insiste Ricoeur (2013). Nesse sentido, para Ricoeur, o si mesmo é uma construção, uma tarefa, nunca é algo pronto, é algo que acontece.

Desta forma, a materialização textual permite que a descrição de experiências humanas alcance um grau de objetivação que auxilie a interpretação e a compreensão do fenômeno investigado. A textualização de experiências (ou o registro escrito de manifestações de um fenômeno da experiência humana) permite o desenvolvimento de uma atividade investigativa mediada que não apenas captura experiências vividas, mas que pode levar também pesquisador e pesquisado(s) a retomá-las, na sua versão mais original, inúmeras vezes, e refletir sobre elas, chegando, potencialmente, a outras interpretações e reinterpretações.

A autobiografia, em poucas palavras, transforma a vida em texto, por mais implícito ou explícito que seja. É só pela textualização que podemos "conhecer" a vida de alguém. O processo da textualização é complexo, uma interminável interpretação e reinterpretação (BRUNER; WEISSER, 1995, p. 149). 
De acordo com M. Freire (2012), a etapa de interpretação do fenômeno, denominada tematização, é um procedimento hermenêutico-fenomenológico típico, realizado a partir de diversas leituras e releituras dos textos coletados, durante a qual podem ser identificados os temas hermenêutico-fenomenológicos que expressam e caracterizam a constituição e a essência do fenômeno investigado. Nessa etapa, iniciam-se os procedimentos de refinamento e de ressignificação $\mathrm{O}$ refinamento consiste na identificação das unidades de significado e avaliação da sua relevância, quando são observados os termos que melhor expressam o significado essencial do fenômeno, suas características fundamentais. Ainda segundo M. Freire, (op.cit., p.193), "Esses procedimentos evidenciam o que metaforicamente associo a um mergulho interpretativo"

Importante, porém, é trazer a visão da autora (ibidem, p. 187), ao afirmar que "os fenômenos da experiência humana são fonte inesgotável de investigação, interpretações e reinterpretações", dificultando, desta forma, o desvendar dos fenômenos em sua totalidade. O processo de tematização apresentado a seguir é parte de um exercício hermenêutico-fenomenológico de compreensão das narrativas coletadas no desenvolvimento desta pesquisa. Sabemos que a identificação dos temas não é uma tarefa simples, ela exige aprofundamento, sintonia e um olhar sensível, atento e minucioso do intérprete para captar o que existe de essencial e intrínseco à natureza do fenômeno observado.

Portanto, depois de muita leitura, de idas e vindas, de explicações e compreensões, apresentamos uma primeira interpretação das narrativas digitais docentes, reconhecendo que não podemos apreender a sua totalidade, apenas tecer aproximações nos pareceram pertinentes às nossas questões.

Os temas hermenêutico-fenomenológicos que emergiram através dos procedimentos interpretativos realizados foram três: Abertura, Desafio $e$ Compromisso. Desta forma, apresentamos a seguir a interpretação desses temas que na tentativa de apreender as diversas manifestações do fenômeno estudado.

\section{A Abertura para si, para a alteridade e para o novo}

É fundamental destacar, inicialmente, que para compreender e atuar neste mundo, a abertura para si mesmo, para o outro e para o novo apresenta-se como uma ação distintiva do humano. Para Heidegger (2009, p. 205), "Como abertura, o compreender sempre alcança toda a constituição fundamental do ser-no-mundo". Assim, se há abertura por parte de quem interpreta, a compreensão já está em princípio disponível. Com certeza, há um trabalho a ser feito, mas a compreensão é alcançável. Como veremos, nas narrativas dos docente analisadas emergem as diferentes faces dessa abertura, como características pessoais que parecem incidir sobre sua formação e uma prática pedagógica inovadora. Para preservar a identidade dos participantes, optamos por indicar apenas as suas iniciais, no excertos extraídos de suas narrativas.

Assim, de modo geral, minha trajetória como aluna não foi marcada pelo uso da tecnologia. O gosto por ela veio no decorrer do período no qual trabalhei em empresas na área administrativa. Iniciei com a máquina de escrever e depois veio o computador. (...) Sinto que o meu gosto pela tecnologia é pela praticidade que ela traz para nossas vidas profissionais e pessoais (L.P.). 
Meu contato com computadores foi quando meu vizinho comprou um...e logo de cara já achei o máximo...ficava babando...mas tinha outra coisa que me atraía (e me atrai até hoje): vídeo games! Passei boa parte da minha adolescência curtindo vários jogos (inclusive, cheguei a trabalhar em locadora de games...) esse contato melhorou minha noção de inglês e meu raciocínio lógico (F.F.).

Quando os professores refletem, em suas narrativas, sobre as experiências vividas com o uso de tecnologia ou meios digitais em suas práticas pedagógicas, o que chama a atenção em primeiro lugar é que eles admitem, claramente, que essas práticas não se originam de suas experiências na educação formal enquanto alunos, mas de vivências pessoais cotidianas, ou seja, de aprendizagens informais. Nesses sentido, insistem sobre três aspectos: a praticidade que a tecnologia oferece para a sua vida e para a sociedade; a curiosidade de conhecê-la; e o prazer que ela traz ao ser utilizada. Essa abertura para o novo, o prático, o prazer demonstra a compreensão que têm os docentes sobre as possibilidades que tais aparatos tecnológicos podem trazer para suas práticas pedagógicas. Essa compreensão se traduz como um abertura existencial que podemos chamar de projeto: "o compreender projeta o ser da presença" e Heidegger (2009, p. 205) afirma que

Este não apenas se abre para o mundo, no sentido de possível significância, mas a liberação de tudo que é intramundano libera esse ente para suas possibilidades. (...) O projeto é a constituição ontológicoexistencial do espaço de articulação do poder-ser fático. E, na condição de lançada, a presença se lança no modo de ser do projeto. O projetar-se nada tem a ver com um possível relacionamento frente a um plano previamente concebido, segundo o qual a presença instalaria o seu ser. Ao contrário, como presença, ela já sempre se projetou e só é em se projetando. Na medida em que é, a presença já se compreendeu e sempre se compreenderá a partir de possibilidades

Essa abertura e a compreensão dela decorrente são traduzidas pelos docente em expressões tais como: "Aprender é responsabilidade do aluno, mas eu, como educadora, tenho que ajudá-lo a entender que o que eu faço é para ajudá-lo.... E o aluno, em suas críticas, me ajuda a aprender a ajudá-lo e me ajuda a aprender a melhorar" (P.D.). Percebemos aqui três faces da abertura. A abertura para a alteridade, que se expressa tanto pelo desejo de ajudar o aluno a compreender a sua ação, quanto pela atitude interior de acatar as suas críticas. Essa abertura para o outro se desdobra numa abertura para si, pois é o aluno quem o ajuda a melhorar. Essa dupla abertura, favorece a uma melhor compreensão de si e do outro como seres aprendentes, o que é reveladora de uma ruptura com as práticas tradicionais e se apresenta como abertura para o novo, para o diferente, para a participação efetiva do aluno, o que conduz a uma busca constante por parte dos docentes para uma maior sintonia com seus alunos e finalmente por parte dos alunos para estimularem o professor a ir além.

\section{Desafios}

A análise das narrativas digitais dos professores permitiu observar que o tema Desafio permeia toda a experiência vivida pelos participantes da pesquisa. Para eles, os desafios consistem em compartilhar, coletivamente, descobertas, aprendizados, boas práticas e romper as barreiras das individualidades, numa ação colaborativa, que 
favoreça a multiplicação de ideias, de conhecimentos e de diferentes culturas. Com efeito, os professores convivem atualmente com muitos alunos que em sua prática cotidiana interagem por várias horas com as novas tecnologias e a escola deve estar preparada para acolher e tornar produtivo esse saber que eles trazem para a escola.

As crianças e os adolescentes - predominantemente nas regiões mais favorecidas - interagem cotidianamente com os novos sistemas de comunicação (...) vivem-nos como naturais e se socializam em seus códigos, formas cognitivas e valores. Chegam à escola com um abundante capital de conhecimentos, concepções ideológicas e préconcepções sobre os diferentes âmbitos da realidade. Frente a esta situação, as instituições educacionais enfrentam o desafio não apenas de incorporar as novas tecnologias da informação como conteúdos do ensino, mas também reconhecer a partir das concepções que as crianças e os adolescentes têm sobre estas tecnologias para elaborar, desenvolver e avaliar práticas pedagógicas que promovam o desenvolvimento de uma disposição reflexiva sobre os conhecimentos e os usos tecnológicos. (LIGOURI, L. 1997, p. 85)

O desafio se constitui na ação de estimular, provocar e ser provocado a realizar algo diferente, inovador que deve ser feito conscientemente na tentativa de buscar melhorias para a ação docente e, consequentemente, para o aprendizado dos alunos. "Com o uso da tecnologia, sinto que o aluno atinge essas competências com mais facilidade e gosto pelo aprendizado (...) Mesclar desafio com conhecimento é, sem dúvida, a fórmula para um aprendizado prazeroso e efetivo" (L.P.).

O desafio se materializa, então, num processo de inovação e implica muitas vezes em rupturas com o que está posto e numa mudança na maneira de fazer educação. Nas narrativas, esses desafios são expressos em ações didáticas que colocam alunos em processos criativos, reflexivos e autorais.

Dentre as minhas práticas pedagógicas, sempre trabalho com o tema "Tecnologia da informação e vida cotidiana", para o desenvolvimento desta prática, trabalho com a leitura de alguns textos com os alunos, sempre buscando relacionar os impactos positivos e negativos das inovações tecnológicas na nossa vida cotidiana. Os alunos são convidados a pensar, buscar e propor inovações tecnológicas que atendam/facilitem as demandas do seu dia a dia. Para minha surpresa e alegria, em 2012 um grupo de alunos, ao pensar nas demandas escolares, propôs e elaborou um jogo sobre a nossa escola, utilizando como ferramenta o minecraft, representando todos os ambientes da Unidade Escolar. A curiosidade e o interesse de alguns alunos é com certeza o que me motiva a sempre propor novos desafios para os alunos. Esse trabalho, como já citado no nosso primeiro encontro, já rendeu para os alunos a participação em dois congressos, o que para mim, como professora, é motivo de muito orgulho, por saber que de alguma forma contribuí direta/indiretamente para o sucesso desses meninos (S. M., grifos nossos).

No excerto acima, vemos que o desafio proposto aos alunos pela professora S. M. foi realizado com tanto êxito que o resultado surpreendeu a própria docente. Observamos também que é com satisfação que ela compartilha o saldo positivo da 
atividade realizada, que extrapolou os muros da escola e expôs a produção dos alunos em eventos acadêmicos que debatem o tema educação e tecnologia. Os resultados do trabalho realizado também motivam a docente para empreender novos desafios, alimentando um processo de contínua evolução. A experiência de outra professora, $\mathrm{M}$. S., também caminhou nessa direção,

O mais difícil foi acreditar nas crianças. Depois das oficinas, discussões, chega o dia de ir ao local para o registro. Dava um frio na barriga... "Essas crianças só querem brincar, não entrevistam, gravam tudo errado, hoje vai gerar um vídeo de 30 segundos..." E sempre, sempre quando eles retornavam, eu recolhia o material para editar sempre me surpreendia com o tanto de registros interessantes... Fui aprendendo a confiar neles! (M. S., grifos nossos).

A relação de confiança, de parceria, nasce da experiência de abertura para a experimentação, para o vivido e realizado, constituindo-se em ato de aprendizagem também para o docente e num processo de autoria para os alunos. Segundo Moran (2014, p. 167):

A educação tem de surpreender, cativar, conquistar os estudantes a todo momento. A educação precisa encantar, entusiasmar, seduzir, apontar possibilidades e realizar novos conhecimentos e práticas. $\mathrm{O}$ conhecimento se constrói com base em constantes desafios, atividades significativas que excitem a curiosidade, a imaginação e a criatividade.

O interessante é que não só os alunos ficaram surpreendidos, cativados e conquistados pelo processo educativo, mas os professores também, dado o seu envolvimento com a atividade proposta, com os sujeitos envolvidos e com os resultados obtidos. Situação que merece destaque é apresentada por outra docente, que se vê desafiada pela condição da classe e resolve buscar alternativa:

Tudo começou com a necessidade de conseguir chamar a atenção dos alunos. (...) Primeiro dia de aula uma verdadeira confusão. Os alunos não queriam prestar atenção. O celular era muito mais importante. A solicitação por saídas para ir ao banheiro, tomar água etc. era uma rotina para elas. Eu precisava conquistá-los (Z. T.).

\section{Compromissos}

Em obra intitulada: Paulo Freire - uma biobibliografia, Gadotti (1996, p. 715) define que compromisso "é a solidariedade com os homens para a busca incessante da humanização" e o compromisso histórico "é o inserir-se, de maneira crítica, na história. O homem assume o dever, como sujeito, de fazer e refazer o mundo".

Para Paulo Freire (1983), reencontrar-se como sujeito e liberar-se é todo o sentido do compromisso histórico. $\mathrm{O}$ autor defende uma educação transformadora, que parta das coisas simples do cotidiano, que se valorize cada ato humano e possibilite ao sujeito sua própria liberação mediante a tomada de consciência de sua capacidade criativa e transformadora. $\mathrm{O}$ instrumento de sua liberação será sempre a prática do diálogo. Um diálogo autêntico que promova o reconhecimento do outro e o reconhecimento de si no outro. Essa atitude revela decisão e compromisso de colaborar na construção de um mundo comum. Para Freire (1983) não há consciências 
vazias, por isso os homens não se humanizam, senão humanizando o mundo. Educar, portanto, envolve a possibilidade de criar e desenvolver a participação política do aprendente rumo à construção e realização de um projeto político e social de liberação.

A análise das narrativas digitais permite depreender diferentes tipos de compromissos que passamos a considerar como um dos subtemas que qualificam o desafio. A narrativa da docente L.P. expressa, por exemplo, o compromisso com o ensino inovador, quando explicita seus sentimentos:

Sinto que estou cumprindo a minha obrigação de professora, pois o ensino não precisa se ater apenas ao currículo preestabelecido, se pudermos oferecer um algo mais ao nosso aluno, por que não fazê-lo? (...) Estudar não precisa ser sempre monótono, maçante, cansativo... pode ser também prazeroso e motivador. (L.P.)

O compromisso com o ensino inovador está explícito na fala de L.P. quando expressa sua preocupação em ter uma ação de constante busca para favorecer a aprendizagem do aluno, pois para L.P., o desafio formativo é a razão maior de ser docente. O compromisso com o ensino inovador traduz-se então em poder oferecer modos de aprender em qualquer lugar e em qualquer tempo para seus alunos, estimulando-os a serem autores, protagonistas, criadores e criativos nesses processos.

Outra modalidade de compromisso que surge um subtema é o compromisso com a aprendizagem contínua. L.P. segue indicando, em sua narrativa, uma atitude reflexiva sobre a importância de sua ação docente, "o que posso fazer além daquilo que já realizo hoje é continuar usando os recursos digitais e ir me atualizando sempre. Não parar de aprender. Para avançar preciso ir a cada dia evoluindo, implantando procedimentos novos... ousando... experimentando..." (L.P.). Retomamos aqui o que afirma Delory-Momberger $(2012$, p. 524) a propósito da reflexão sobre si mesmo, o que permite "(...) mostrar como a inscrição forçosamente singular da experiência individual em um tempo biográfico se situa na origem de uma percepção e de uma elaboração peculiar dos espaços da vida social".

O compromisso ético-político é a terceira modalidade que aparece nas narrativas dos professores. Esse compromisso pode vir a ser a força motriz capaz de catalisar a construção de um mundo menos discriminatório e mais humano, realizado por homens e mulheres comprometidos com a justiça, a democracia, a diversidade e a ética neste século. Possuir compromisso ético-político com o outro é compreender que o processo de formação do aluno precisa ser crítico, promover a reflexão e ser pautado por valores como solidariedade, humanidade, ética, amor, dignidade, respeito pelos outros, conforme a natureza da democracia, nos diz Pinheiro (2013, p.65-66). A fala de Z. T. ilustra esse compromisso docente que ultrapassa os limites estabelecidos pelo currículo e pelo espaço físico da sala de aula.

Depois de refletir um pouco, chego à conclusão que o que eu faço é exatamente o contrário do que fizeram comigo. Eu quero fazer diferente. Quero fazer a diferença. Não quero que meus alunos se sintam um número. Quero que se sintam pessoas, seres humanos, individuais e especiais (Z. T.).

Outros temas e subtemas se revelaram no processo de tematização da análise hermenêutico-fenomenológica, mas como afirmamos no início, elegemos para este artigo apenas três temas: abertura, desafio e compromisso, por expressarem com 
muita profundidade a riqueza encontrada nas narrativas dos docentes participantes da pesquisa.

\section{Considerações finais}

Num processo contínuo de "caminhar para si" (JOSSO, 2010), os participantes da pesquisa mergulharam numa viagem rumo à compreensão de como se tornaram o que são, através de relatos de um conjunto de experiências vividas com uso de tecnologia em suas práticas, e no decorrer da pesquisa-formação eles tomaram consciência da riqueza das suas experiências, do quanto é importante aquilo que fazem, e puderam igualmente perceber que o que fazem pode tocar o outro, seus colegas professores, seus alunos, e transformá-los.

Quando os docentes narram suas experiências com o uso de meios digitais em suas práticas pedagógicas com TDIC, percebemos que a abertura dos participantes constitui-se elemento fundamental que lhes permitiu mesclar os conhecimentos dos conteúdos curriculares com o conhecimento que alunos e professores também têm de novos recursos de TDIC, dando assim mais liberdade criadora e possibilidade de autoria a todos os envolvidos no processo. Dessa forma, as narrativas, ricas em experiências diferenciadas, nos ajudam a compreender como eles rompem com os moldes da aula tradicional, como expressam em suas histórias de vidas que estão dispostos a compartilhar, a trocar, a fazer novas escolhas, a superar as expectativas de seus alunos através do seu trabalho.

As inúmeras leituras, as idas e vindas aos textos, os movimentos de tematização, textualização, refinamento e ressignificação que configuraram os temas aqui apresentados, contribuíram de forma significativa para uma melhor percepção do fenômeno investigado e para uma compreensão mais aprofundada dos elementos constitutivos da relação educação/tecnologia.

A escrita autobiográfica, nesse sentido, configurou-se como um ato viabilizador da autorreflexão e invenção de si, através de um mergulho na experiência vivida promovido pelas ações da pesquisa-formação.

\section{REFERÊNCIAS}

ARENDT, H. Entre o passado e o futuro. São Paulo: Perspectiva, 2005.

BRUNER, J. Fabricando histórias. Direito, literatura, vida. São Paulo: Letra e Voz, 2014.

DELORY-MOMBERGER, C. Biografia e educação: figuras do indivíduo-projeto. Tradução de Maria da Conceição Passeggi, João Gomes da Silva Neto, Luis Passeggi. São Paulo: PAULUS, Natal: EDUFRN, 2008. (Coleção Pesquisa (Auto) BiográficaEducação).

A condição biográfica: ensaios sobre a narrativa de si na modernidade avançada. Tradução de Carlos Galvão Braga, Maria da Conceição Passeggi, Nelson Patriota. Natal, RN: Natal: EDUFRN, 2012. 
Abordagens metodológicas da pesquisa biográfica. In: Revista Brasileira de Educação. Rio de Janeiro, v. 17, n. 51 set/dez, 2012.

FREIRE. M. M. Da aparência à essência: a abordagem Hermenêutico-fenomenológica como orientação qualitativa de pesquisa. In: ROJAS, J.: STREINGHETA, L. M. (Orgs.). Educação, pesquisa e prática docente em diferentes contextos. 1ed. Life Editora, 2012.

2010. A Abordagem Hermenêutico-fenomenológica como orientação de pesquisa. In FREIRE, M. M. (org.). A pesquisa qualitativa sob múltiplos olhares: estabelecendo interlocuções em Linguística Aplicada. Publicação do GPeAHF, Grupo de Pesquisa sobre a Abordagem HermenêuticoFenomenológica. 2010.

FREIRE, P. Pedagogia do oprimido. $12^{\mathrm{a}}$ edição, Rio de Janeiro: Paz e Terra, 1983. Educação como prática da liberdade. $15^{\mathrm{a}}$ edição, Rio de Janeiro: Paz e Terra, 1983.

GADOTTI, M. (Org.) Paulo Freire - uma biobibliografia. São Paulo: Cortez, 1996.

HEIDEGGER, M. Ser e tempo. $4^{\text {a }}$ ed. Petrópolis: Vozes, 2009.

JOSSO, M.-C. Experiências de vida e formação. 2. ed. Natal, RN: EDUFRN; São Paulo: Paulus, 2010.

LIGOURI, L. M. As novas tecnologias da informação e da comunicação no campo dos velhos problemas e desafios educacionais. In: LITWIN, E. (org.) Tecnologia educacional: politica, história e propostas. Porto Alegre: Artes Médicas, 1997.

MORAN, J. M. A educação que desejamos: novos desafios e como chegar lá. 5. ed. Campinas: Papirus, 2014.

NÓVOA A.; FINGER, M.; Introdução. In: NÓVOA, A.; FINGER, M. (Org.). O método (auto)biográfico e a formação. Natal: EDUFRN; São Paulo: Paulus, 2010, p.21-29.

PASSEGGI, M. C.; BARBOSA, T. M. N; CÂMARA, S. C. X. Gêneros acadêmicos autobiográficos: desafios do GRIFARS. In: SOUZA, E. C.; PASSEGGI, M. C. (Org.). Pesquisa (auto) biográfica: cotidiano, imaginário e memória. Natal/RN:EDUFERN; São Paulo: Paulus, 2008.

A formação do formador na abordagem autobiográfica. A experiência dos memoriais de formação. In: SOUZA, E. C.; ABRAHÃO, M. H. M. B. (Orgs.). Tempos, narrativas e ficções: a invenção de si. Porto Alegre: EDIPUCRS: EDUNEB, 2006, p. 203-218.

. Mediação Biográfica: figuras antropológicas do narrador e do formador. In:

PASSEGGI, M. C.; BARBOSA, T. (Org.). Memórias, memoriais: pesquisa e formação docentes. Natal, RN:EDUFRN; São Paulo: Paulus, 2008, v. 05, p. 43-59.

Memoriais: injunção institucional e sedução autobiográfica. In: PASSEGGI, M. C.; SOUZA, E. C. (Orgs). (Auto)Biografia: formação, territórios e saberes. Natal: EDUFRN, São Paulo: PAULUS, 2008a, p. 103 - 131.

Narrar é humano! Autobiografar é um processo civilizatório. In: PASSEGGI, M. C.; SILVA, V. B. (Orgs.). Invenções de vidas, compreensão de itinerários e alternativas de formação. São Paulo: Cultura Acadêmica, 2010, p. 103-130. 
. Memorial autobiográfico: o reconhecimento de si como sujeito aprendente. In: Ana Luiza Grilo Balassiano e Lia Faria. (Org.). Caminhos da educação Franco Brasileira: memórias e identidade. 1ed.Rio de Janeiro: EdUERJ, 2013, v. 1, p. 125134.

RICOEUR, P. Teoria da Interpretação: O discurso e o excesso de significação. Lisboa/Portugal: Edições 70, 2013.

PINHEIRO, S. Formar para diferenciar professores do Século XXI - Explicitando o (Im)Previsível nas Licenciaturas em Ciências Biológicas. 2013. 156f. Tese (Doutorado em Educação em Ciências e Matemática). Universidade Federal do Pará, Programa de Pós-Graduação em Educação em Ciências e Matemáticas, Belém, 2013. 